\title{
DUNIA MODE DAN BIDANG USAHA PEMBUATAN BUSANA
}

\author{
Hotmaria Tampubolon*) \\ Surel: Tampubolonmariao@gmail.com
}

\begin{abstract}
From time to time, clothing stores sell clothing with unique cutting styles. This piece of clothing style captured the hearts of buyers, so clothing that some time before was very popular, had to be abandoned, that's the appearance of a fashion phenomenon. By "fashion" is meant a way of dressing with a style cut or style that is more accepted by a group of people at a certain time. Fashion that comes from the west, quickly imitated by men and women. Sometimes the mode initially gets criticized, because it feels unsuitable or clumsy. Gradually many people choose and follow the latest fashion for fear of getting the title "missed mode". Growing rapidly between nations, the more people recognize the various cultures affecting each other. This communication also influences the development of fashion. To follow the flow of fashion well, we need to know the basic style of a fashion that must reappear in the next mode with a difference in the short length of the skirt. Thus fashion that has a basic style will last longer, which means that fashion is not quickly behind fashion, so it also saves finance.
\end{abstract}

Keywords; Fashion business

\section{PENDAHULUAN}

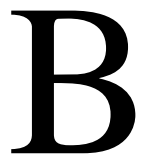

usana sebagai bagian dalam kehidupan manusia tidak asing lagi bagi masyarakat umum Indonesia, artinya busana merupakan sebuah gaya hidup yang diminati dan disenangi dari usia orang tua, remaja hingga anak-anak. Pemakaian busana tidak terbatas pada $\mathrm{ru}^{1}$ ang dan waktu, serta golongan ekonomi bawah, menengah dan atas sangat membutuhkan busana. Fenomena ini tentu memberikan angin segar bagi orang-orang yang ingin membuka usaha busana, apalagi saat ini bisnis (usaha) busana sedang mengalami perkembangan pesat, oleh karena busana tidak hanya sekedar sebuah kebutuhan, tetapi sudah sebagai gaya hidup seseorang. Peluang usaha busana yang tidak mengenal kata rugi akan mengelola dan memasarkan usaha busana dengan baik serta memanfaatkan kesempatan adalah sebagai peluang yang menguntungkan dalam usaha busana.

Secara otomatis semakin banyak orang yang meminati busana dan mengenakannya, permintaan busanapun akan semakin meningkat, sehingga dimasa yang akan datang prospek usaha busana semakin berkembang karena peminat busana akan terus bertambah dari waktu ke waktu, baik dalam kesempatan apapun dan dimanapun kita berada. Sebagai seorang yang berkecimpung dalam dunia busana baik dari segi disain, produksi, menghias busana dan handycraff hal ini akan menjadi peluang usaha busana.

\footnotetext{
* Dra. Hotmaria Tampubolon, M.Pd. Dosen

Jurusan Tata Busana FT UNIMED
} 
PEMBAHASAN

\section{Perkembangan \& Peluang Bisnis}

Busana

\section{A. Gaya hidup}

Busana sebagai gaya hidup seseorang dapat menunjukkan status social, golongan, etnis, bahkan sifat seseorang. Sebelum busana dikenakan oleh seseorang, busana dipilih berdasarkan warna, model, bahan dan terakhir adalah harga, artinya bila busana sudah disenangi dan dipilih untuk dikenakan maka akan sangat mendapat tempat dan perhatian oleh sese orang, sehingga tidak menjadi penghalang dari segi biaya yang harus dikeluarkan.

Busana sebagai salah satu kebutuhan sandang manusia, saat dirumah, berbelanja ataupun bekerja dan pesta sudah menjadi gaya hidup bahkan hobi (kesenangan) seseorang, tidak hanya sebagai kebutuhan dasar manusia untuk menutupi tubuh dari pengaruh luar/iklim.

Selain warna, gaya dan model busana yang ditawarkan saat ini, ditambah dengan pemakaian assesories dan pelengkap, serta siapakah pemakai busana tersebut apakah ia dari seorang yang dikenal (selebritis, seorang tokoh, bangsawan dsb) maka busana akan sangat disambut serta diminati, sehingga gaya hidup berbelanja busana sangat tinggi.

\section{B. Trend Busana Dari Masa Ke Masa}

Perkembangan busana secara Internasional dan Nasional (Indonesia), memiliki perkembangan yang tersendiri. Di Indonesia perkembangan busana tidak sehebat perkembangan busana di tingkat dunia yang dapat terjadi dengan sangat begitu cepat, ibarat hitungan waktu dari minggu ke minggu ( tv fashion dari jaringan tv kabel) tidak hanya karena melalui perubahan iklim, harihari khusus seperti Valentine, X ,Mas, dll.Kini, perkembangan busana lebih terlihat dengan kreativitas para perancang busana yang terus menyerap trend mode dunia.

Di Indonesia perkembangan busana juga sudah mulai mengikuti perkembangan busana secara International, namun masih pada kalangan tertentu (selebritis atau seorang pengusaha), perkembangan masih lebih mengutamakan hari-hari khusus seperti Idul-Fitri, dan Natal, untuk perubahan iklim tidaklah sangat mempengaruhi oleh karena Indonesia memiliki iklim Tropis yang lebih dominan.

Sama seperti mode busana lainnya, tren yang dijadikan kiblat bagi perancang busana Indonesia adalah yang berkembang di Eropa dan Asia seperti Prancis, Amerika, Inggris dan dan Jepang serta Cina. Namun juga, didukung oleh kayanya budaya yang ada di Indonesia, desainer atau perancang busana juga banyak yang bereksperimen dengan material lain atau mengadaptasi pakaian tradisional 
Indonesia (busana daerah). Dengan demikian trend kembali ke budaya Nusantara seakan menjadi salah satu ciri perkembangan busana Indonesia.

$$
\text { Meningkatnya antusiasme }
$$

masyarakat dalam menggunakan busana, membuat bisnis busana juga semakin meningkat dengan subur. Meskipun biasanya masa penjualan tertinggi adalah menjelang hari- hari besar, tetapi bisnis ini tidak akan kehilangan pasarnya pada hari biasa, oleh karena busana tetap diperlukan pada aktivitas sehari-hari.

\section{Desain Busana}

Disain busana adalah rancangan suatu gagasan di bidang busana yang memungkinkan orang mewujudkan bendanya. Disain busana mencakup unsur-unsur silhouette atau garis luar bentuk pakaian, bahan, warna, dekorasi dan pelengkap yang menyertainya. Disain busana dikatakan baik, jika dapat mencapai suatu keserasian antara hubungannya dengan sipemakai, tempat dan waktu.

Disain busana mempertimbangkan nilai baik buruk tentang:

1. Perbandingan antara bagianbagiannya

2. Keseimbangan antara bagian kiri dan bagian kanan

3. Pusat perhatian yang menyatu tidak terpecah belah

4. Irama menyenangkan, dinamis, tidak menjemukan

5. Kesatuan persesuian dan ketergantungan antara bagian-bagiannya, sehingga tak dapat dipisah-pisahkan.

Contoh-contohnya sebagai berikut:

\section{Perbandingan}

Sebagai contoh perbandingan yang seimbang adalah, antara besar topi, tas, lebar ikat pinggang, bentuk dan tinggi sepatu, berbanding serasi dengan panjang dan bentuk gaun. Atau panjang dan kembang blus sebanding dengan ketat atau kembang rok. Corak dan warna pada bidangbidang tertentu sebanding dengan bentuk badan. Jika tinggi tubuh dibagi menjadi dua bagian oleh suatu garis hias atau garis pinggang, maka perbandingan bagian atas dan bawah 1:5, 1:3 dan 3:4 adalah lebih baik dari pada $1: 1$ atau 2:3.

\section{Keseimbangan}

Keadaan seimbang mempunyai cirri-ciri bahwa bagian kiri dan kanan berbobot sama. Adakalanya bersifat simetris, atau bersifat a-simetris, misalnya jika model bagian kanan dan bagian kiri tepat sama, disebut keseimbangan simetris. Sebaliknya, jika bagian kiri dan kanan berlainan bentuk komposisinya tetapi berbobot sama, disebut keseimbangan asimetris. (gambar 1-6a)

\section{Pusat Perhatian}

Disain yang baik mempunyai kesan, bahwa bagian-bagian yang lain seakan-akan tunduk pada satu bagian tertentu, yang disebut pusat perhatian. Biasanya, pusat perhatian diletakkan 
didekat wajah. Maksud sebenarnya untuk menonjolkan yang indah, atau untuk memindahkan perhatian orang lain dari bagian tubuh yang kurang baik, kebagian yang menjadi imbangannya. Misalnya jika seseorang berpanggul besar, maka pusat perhatian diletakkan di badan atas. Warna rok yang tua, sedamg warna blus dipilih yang lebih terang. Apabila dalam berpakaian terdapat beberapa pusat perhatian, akan memeberi kesan norak atau ramai (gambar 1-7)

\section{Irama}

Sejalan dengan irama music, maka dalam busana terdapat irama yang berasal dari pilihan pusat perhatian, bergerak menuju perulangannya, dan membentuk jalingan hubungan, yang member kesan tertentu. Perulangan unsureunsur tersebut mempunyai variasi yang berbeda-beda, misalnya warna gaun seseorang lebih tua dari pada warna kulitnya. Warna ini berulang lebih muda pada warna sepatunya, dan berikut warna yang lebih muda lagi pada perhiasan rambutnya. Variasi yang lain bertolak dari klep saku dalam pada dada. Bentuk klep tersebut beralih pada klep saku rok yang lebih besar (gambar I-6b).

\section{Kesatuan}

Perpaduan antara nilai-nilai
disain yang dapat mencapai
kesesuaian, menimbulkan suatu
keselarasan atau harmoni. Bagian-
bagian pakaian itu menjadi satu
kesatuan. Unsur-unsur disain yang

dapat menghimpun akan menonjol dan member watak pada busana tersebut.

Harmoni akan terganggu jika pelengkap pakaian, seperti tas, sepatu, ikat pinggang, perhiasan, tidak sesuai dalam bentuk maupun warnanya. Misalnya sepatu sport adidas tidak sesuai dengan gaun sore, perhiasan yang dikenakan terlalu menyolok untuk kesempatan tertentu.

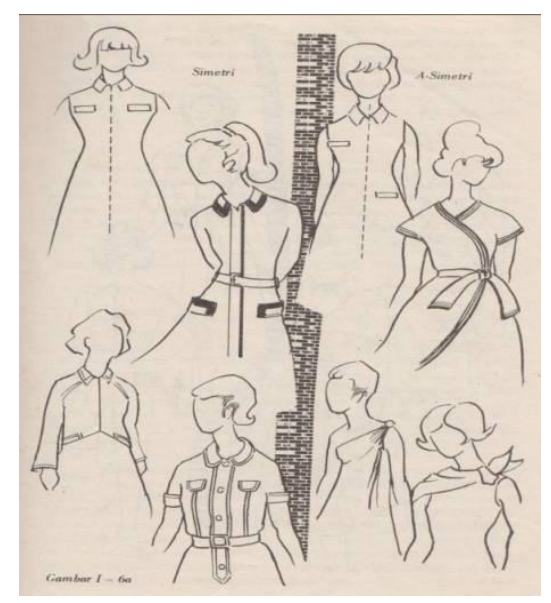

Gambar 1-6a

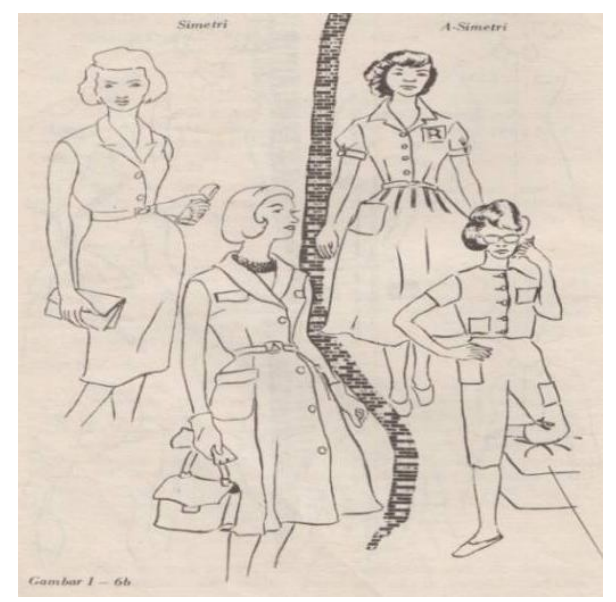

Gambar 1-6b 


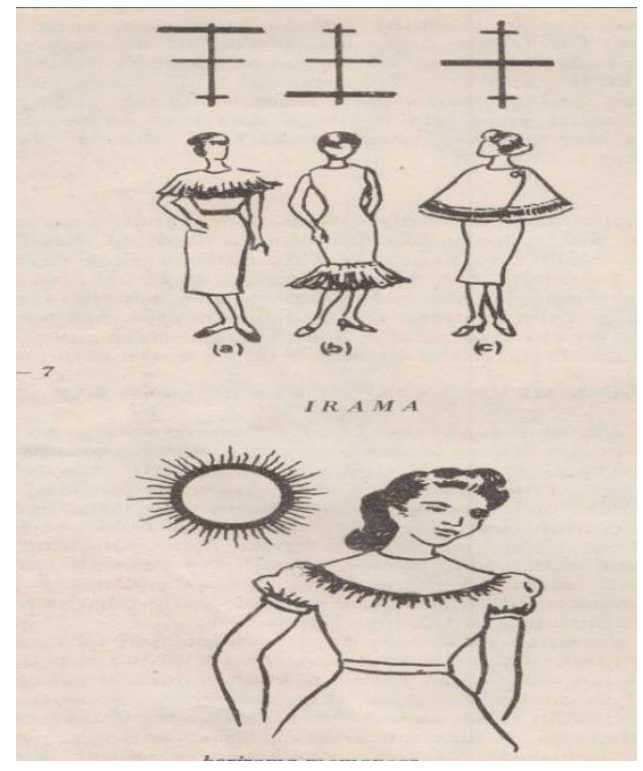

Gambar 1-7

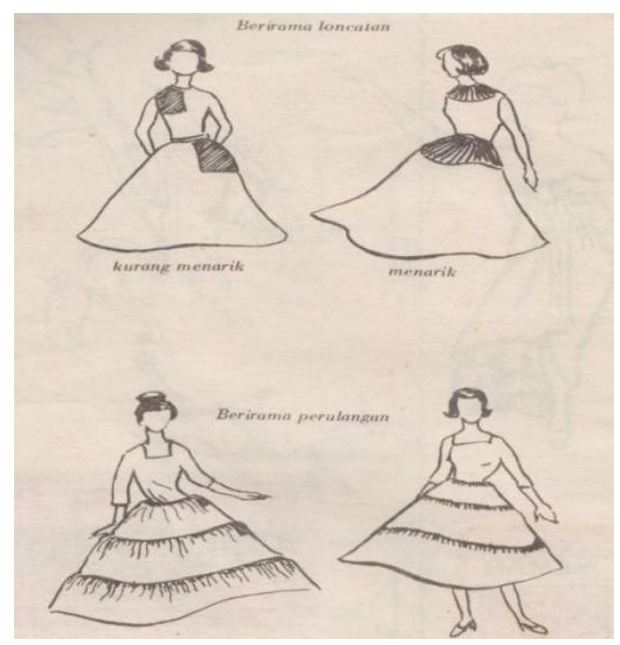

Gambar 1-7

Dalam bidang usaha busana ada bentuk-bentuk yang perlu kita kenali, seperti;

\section{Houte Couture}

Houte Couture adalah sistim penjahit tingkat tinggi. Struktur organisasi rumah mode ini mempunyai perancang-perancang mode yang selalu menciptakan modelmodel yang baru untuk tiap-tiap musim. Model busana dibuat menurut ukuran pragawati-pragawatinya, dan dipasarkan untuk kelompok tertentu sejumlah koleksi busana dalam suatu pameran mode. Model untuk musim panas yang akan dating dipentaskan beberapa bulan sebelum musim itu tiba. Busana-busana dibuat dengan sangat teliti dan teknik penyelesaiannya yang mencerminkan penguasaan teknik jahit yang tinggi.

\section{Boutique}

Boutique adalah suatu toko busana yang menjual busana jadi serta pelengkap busana lainnya. Misalnya tas, sepatu, ikat pinggang, topi, corsage, kancing-kancing, gesper, dll. Toko ini juga melayani pembeli yang perlu mencocokkan busana jadi denganukurannya. Selain itu menerima pesanan jahitan menurut selera pemesan. Biasanya model diambil dari majalah-majalah mode.

\section{Atelier}

Atelier atau workshop adalah toko yang khusus melayani pesanan pembuatan busana menurut model dan ukuran pemesan.

\section{Pabrik Konfeksi}

Pabrik konfeksi adalah pabrik busana jadi. Busana dibuat dengan ukuran baku sehingga orang tinggal memilih ukuran yang sesuai dengan bentuk badannya. Tanda yang dipakai untuk mengenal jenis ukuran tersebut 
adalah S (small), $\mathrm{M}$ (medium), $\mathrm{L}$ (large), LL (extra large).

Disamping itu sering disertakan tanda-tanda atau petunjuk cara pemeliharaan. Sistim pembuatan busana di pabrik konfeksi mengikuti sistim ban berjalan, dari satu mesin ke mesin berikutnya, merupakan suatu pekerjaan yang beranting. Pekerja hanya mengerjakan sebagian kecil penyelesaian untuk satu busana, tetapi berulang dalam jumlah yang banyak. Semua teknik penyelesaian dikerjakan dengan mesin.

\section{Kemajuan Teknologi Tekstil}

Dewasa ini kemajuan teknologi memungkinkan terciptanya aneka ragam dalam jenis busana dan gunanya, pemasarannya sangat diperhatikan. Tekstil ini di jual sebagai barang tekstil atau dalam bentuk pakaian jadi. Pihak produsen telah jauh mempelajari apa-apa yang dikehendaki dan diperlukan oleh konsumen. Misalnya dalam menawarkan contoh-contoh tekstil disertakan pula model-model yang sesuai dengan jenis pakaiannya seperti dapat kita lihat di toko modern, etalase atau ruang pameran tekstil dan pakaian jadi, diatur sangat menarik, serta dikombinasikan dengan pelengkap busana.

Tujuannya untuk memperkenalkan produk yang baru akan menimbulkan selera konsumen untuk membeli.

Seorang konsumen sekaligus dapat mempelajari tentang bahan tekstil yang diperkenalkan, model yang cocok untuk masing-masing tekstil, keserasian warna dan susunan busana dengan pelengkapnya yang cocok. Pengenalan demikian akan menambah pengetahuan, disamping itu perasaan tidak akan ketinggalan dapat berakibat, bahwa seseorang berbelanja di luar rencananya. Keadaan ini sangat rawan bagi ekonomi keluarga. Adakalanya karena mengikuti mode anggaran belanja untuk busana lebih besar daripada anggaran yang disediakan untuk makanan atau keperluan lain.

\section{PENUTUP}

Busana merupakan salah satu kebutuhan yang termasuk kebutuhan primer manusia. Kemajuan teknologi membawa perbaiakan-perbaikan dalam cara berbusana dan jenis busana yang dikenakan.

Dunia mode dan bidang usaha pembuatan busana merupakan sumber pengetahuan tentang masalah busana yang perlu dipelajari.

Pengenalan seni tentang busana terdapat dalam unsure-unsur disain yang erat hubungannya dengan seni berbusana.

Peluang usaha busana yang tidak mengenal kata rugi akan mengelola dan memasarkan usaha busana dengan baik serta memanfaatkan kesempatan adalah sebagai peluang yang menguntungkan dalam usaha busana. 


\section{DAFTAR PUSTAKA}

Arifah A. Riyanto, Teori Busana, Penerbit Yapemdo Bandung, 2003.

Ahmad Sahidin, Modal Mini Hasil Maksi, Salamadani Pustaka Semesta, Bandung, 2002.
Diyah Musri Harsini \& Fenty Nadia, Bisnis Busana, Penebar Plus, Jakarta, 2002.

Nadia Indiwara, Untung Besar Duduk Doang, Indonesia Cerdas, Yogyakarta, 2008.

Nuraini Sutantyo \& Radias Saleh, Tata Busana I, Departemen Pendidikan \& Kebudayaan, Jakarta, 2000. 